\title{
Removal of Trace Metals from Municipal Wastewater by Coagulation-Flocculation
}

\author{
Andrew Hargreaves ${ }^{1}$, Peter Vale ${ }^{2}$, Jonathan Whelan ${ }^{2}$, Carlos Constantino ${ }^{3}$, Gabriela Dotro ${ }^{1}$, \\ Pablo Campo ${ }^{1}$ \\ ${ }^{1}$ Cranfield University \\ Bedford, MK43 0AL, UK \\ ${ }^{2}$ Severn Trent Water \\ Coventry, CV1 2LZ, UK \\ ${ }^{3}$ Atkins, Oxford, OX29 4AH, UK \\ a.j.hargreaves@cranfield.ac.uk
}

\section{Extended Abstract}

As a consequence of their potential to cause harm, there are strong regulatory drivers that require metals to be removed as part of the wastewater treatment process. Bioavailability-based standards have recently been specified for $\mathrm{Cu}, \mathrm{Pb}, \mathrm{Ni}$ and $\mathrm{Zn}$ and are expected to reduce acceptable metal concentrations. In order to comply with these standards, wastewater treatment works may require new treatment types to enhance metal removal and it is, therefore, important to examine potential treatment options.

A previous study found that a substantial proportion of $\mathrm{Cu}, \mathrm{Pb}, \mathrm{Ni}$ and $\mathrm{Zn}$ in effluent is adsorbed to or complexed with macromolecules (e.g. proteins, polysaccharides, aminosugars, etc.) that are typically present in the colloidal size fraction. Thus technologies capable of removing colloidal particles have good potential to enhance metals removal from wastewater. Coagulation-flocculation (CF) has been shown to effectively remove colloidal particles, however, few studies have comprehensively compared the effectiveness of the three primary coagulants, namely; metal salts, synthetic polymers and biopolymers.

The present study investigated the effectiveness of $\mathrm{CF}$ at removing trace metals from humus effluent using the following coagulants; ferric chloride $\left(\mathrm{FeCl}_{3}\right)$, the synthetic polymer polyethyleneimine (PEI), and the biopolymers chitosan and Floculan. Effluent samples were collected from a trickling filter treatment works operating in the UK. Using jar tests, the influence of coagulant dosage and the velocity and time of the slow mixing stage were studied. Chitosan and PEI had a moderate effect on the removal of trace metals $(\leq 35 \%)$. $\mathrm{FeCl}_{3}$ removed $48 \% \mathrm{Cu}, 56 \% \mathrm{~Pb}$ and $41 \% \mathrm{Zn}$ at the recommended dose of $0.10 \mathrm{mg} / \mathrm{L}$. At the recommended dose of $0.25 \mathrm{mg} / \mathrm{L}$ Floculan removed $77 \% \mathrm{Cu}, 68 \% \mathrm{~Pb}$ and $42 \% \mathrm{Zn}$. The elimination of $\mathrm{Ni}$ was negligible for Floculan; additionally, $\mathrm{Ni}$ concentrations were significantly increased in effluent treated with $\mathrm{FeCl}_{3}$. In fact, a linear relationship between $\mathrm{FeCl}_{3}$ dosage and $\mathrm{Ni}$ concentration was observed in treated effluent. Thus, the use of $\mathrm{FeCl}_{3}$ may pose a potential risk to compliance with Environmental Quality Standards for Ni.

High turbidity removal achieved in conjunction with negative zeta potentials indicated that charge neutralisation did not play a significant role in the removal of particles from effluent when treated with $\mathrm{FeCl}_{3}$. As such, the sweep flocculation mechanism, which is not influenced by the properties of particles (i.e. negatively charged particles can become entrapped in precipitates), was deduced as the main removal mechanism. Floculan is composed of polymeric chains with cationic charge that neutralise particles, as indicated by data on zeta potential, enabling aggregation and removal through the mechanism of inter-particle bridging.

This study was one of the first of its kind to investigate the effectiveness of the CF treatment process for the elimination of trace metals (in the $\mu \mathrm{g} / \mathrm{L}$ range) from municipal wastewater. Overall, $\mathrm{FeCl}_{3}$ and Floculan were found to be most effective at removing trace metals.

Keywords: Coagulation-flocculation, trace metals, jar test, wastewater 